\title{
Absolute Radiometric Calibration of KOMPSAT-3A
}

\author{
H. Y. Ahn ${ }^{\text {a }}$ D. Y. Shin ${ }^{\mathrm{a}}$, J. S. Kim ${ }^{\mathrm{a}}$, D. C. Seo ${ }^{\mathrm{b}}$, C. U. Choi ${ }^{\mathrm{a} *}$ \\ ${ }^{a}$ Dept. of Spatial Information Engineering, Pukyong National University 45, Yongso-ro, Nam-gu, 45813 Rep. of KOREA - \\ hyahn85@pukyong.ac.kr \\ ${ }^{\mathrm{b}}$ Data Processing \& Cal/Val Team, Korea Aerospace Research Institute, 169-84, Gwahak-ro, Yuseong-gu, Daejeon, 34133, Rep. of \\ KOREA - dcivil@kari.re.kr
}

Commission I, WG I/4

\section{KEY WORDS: Radiometric Calibration, TOA Radiance, KOMPSAT-3A, Radiative Transfer Code}

\begin{abstract}
:
This paper presents a vicarious radiometric calibration of the Korea Multi-Purpose Satellite-3A (KOMPSAT-3A) performed by the Korea Aerospace Research Institute (KARI) and the Pukyong National University Remote Sensing Group (PKNU RSG) in 2015.The primary stages of this study are summarized as follows: (1) A field campaign to determine radiometric calibrated target fields was undertaken in Mongolia and South Korea. Surface reflectance data obtained in the campaign were input to a radiative transfer code that predicted at-sensor radiance. Through this process, equations and parameters were derived for the KOMPSAT-3A sensor to enable the conversion of calibrated DN to physical units, such as at-sensor radiance or TOA reflectance. (2) To validate the absolute calibration coefficients for the KOMPSAT-3A sensor, we performed a radiometric validation with a comparison of KOMPSAT-3A and Landsat-8 TOA reflectance using one of the six PICS (Libya 4). Correlations between top-of-atmosphere (TOA) radiances and the spectral band responses of the KOMPSAT-3A sensors at the Zuunmod, Mongolia and Goheung, South Korea sites were significant for multispectral bands. The average difference in TOA reflectance between KOMPSAT-3A and Landsat-8 image over the Libya 4, Libya site in the red-green-blue (RGB) region was under 3\%, whereas in the NIR band, the TOA reflectance of KOMPSAT-3A was lower than the that of Landsat- 8 due to the difference in the band passes of two sensors. The KOMPSAT-3Aensor includes a band pass near $940 \mathrm{~nm}$ that can be strongly absorbed by water vapor and therefore displayed low reflectance. Toovercome this, we need to undertake a detailed analysis using rescale methods, such as the spectral bandwidth adjustment factor.
\end{abstract}

\section{INTRODUCTION}

KOrea Multi-Purpose SATellite (KOMPSAT)-2 and -3 were commissioned to satisfy the demand for high-resolution satellite images in Korea. On March 26, 2015, KOMPSAT-3A was launched successfully, and Calibration and Validation $(\mathrm{Cal} / \mathrm{Val})$ began recently to improve image quality during the Launch and Early Operation Phase (LEOP). Cal/Val is divided into three parts: geometric, radiometric, and spatial. In this paper, we report the results of the radiometric $\mathrm{Cal} / \mathrm{Val}$ of the spectral application images.

Since launching the KOMPSAT series, their imagery has been radiometric characterized by the Korea Aerospace Research Institute (KARI) and the Pukyong National University Remote Sensing Group (PKNU RSG) (Kim et al. 2015; Lee et al. 2012). In this paper, post-launch in-flight calibration was conducted to promote the stable operation of KOMPSAT-3A during the LEOP. The study was comprised of three main stages:

(1) A field campaign to determine radiometrically calibrated target fields was conducted in Mongolia and South Korea. Surface reflectance data obtained during the campaign were input into a radiative transfer code (RTC) to predict sensor radiance. From this, equations and parameters were derived for the KOMPSAT-3A sensor to enable conversion of calibrated DNs to physical units.

(2) We assessed the calibration coefficients with radiometric validation by comparing KOMPSAT-3A and Landsat- 8 TOA reflectance using a Pseudo Invariant Calibration Site (PICS).

\section{MEHTOD}

In this study, absolute radiometric calibration of KOMPSAT-3A AEISS-A was initiated using a reflectance-based method. This method is widely used to individually evaluate the radiometric function of satellites (Naughton et al. 2011).

In May and June 2015, a field campaign was performed in Goheung, South Korea, and Zuunmod, Mongolia, to calculate the absolute calibration coefficient using a reflectance-based vicarious method, which was calculated from the field campaign results and cross-calibration (Table 1).

\begin{tabular}{|c|c|c|c|c|c|c|c|}
\hline \multirow{2}{*}{ Site } & \multirow{2}{*}{ Sensor } & \multirow{2}{*}{ Date } & \multirow{2}{*}{$\begin{array}{l}\text { Time } \\
\text { (UTC) }\end{array}$} & \multicolumn{2}{|c|}{ Sun $\left(^{\circ}\right)$} & \multicolumn{2}{|c|}{ Satellite $\left(^{\circ}\right)$} \\
\hline & & & & SZA & SAA & SZA & SAA \\
\hline \multirow{4}{*}{ Goheung } & \multirow{6}{*}{$\mathrm{K} 3 \mathrm{~A}$} & $05 / 26$ & $04: 45$ & 23.2 & 240.2 & 33.0 & 262.8 \\
\hline & & $05 / 27$ & $04: 53$ & 21.3 & 236.3 & 9.9 & 261.4 \\
\hline & & $05 / 28$ & $04: 43$ & 19.4 & 231.9 & 16.2 & 80.0 \\
\hline & & $06 / 17$ & $05: 57$ & 27.5 & 231.5 & 18.8 & 260.5 \\
\hline \multirow[t]{2}{*}{ Zuunmod } & & $06 / 18$ & $05: 47$ & 26.6 & 208.7 & 2.8 & 78.6 \\
\hline & & $06 / 19$ & $05: 36$ & 25.8 & 203.5 & 23.4 & 76.7 \\
\hline \multirow{2}{*}{ Libya-4 } & $\mathrm{K} 3 \mathrm{~A}$ & $07 / 15$ & $11: 37$ & 17.9 & 240.5 & 3.3 & 76.6 \\
\hline & L8 & $07 / 15$ & $08: 54$ & 23.9 & 108.3 & \multicolumn{2}{|c|}{ Nadir } \\
\hline
\end{tabular}

Table 1. Metadata of images in this study

Direct, diffuse, and total solar radiance energy were measured with a MultiFilter Rotating Shadow band Radiometer (MFRSR) and weather parameters (i.e., air pressure, relative humidity, air

\footnotetext{
* Corresponding author :cuchoi@pknu.ac.kr
} 
temperature, wind direction, wind velocity, and visibility) were measured with a PTU-2000 (Yankee Environmental Systems, Turners Falls, MA, USA) and Automatic Weather System (AWS). The surface reflectance data measured in field campaigns and the atmospheric condition parameters, such as meteorological conditions and ozone, water vapour and aerosols, were input to a radiative transfer code that predicts the TOA radiance.

To evaluate the absolute calibration coefficient using a vicarious approach for KOMPSAT-3A, it was cross-validated with the Landsat-8 OLI sensor and TOA reflectance using the Libya-4 PICS.

\subsection{Field Campaign}

The field campaign conducted in Zuunmod (lat $47.709^{\circ}$, lon $106.990^{\circ}$ ), Mongolia, satisfied all of the conditions and was easily accessible. However, it was difficult to find a site in Korea that satisfied all of the conditions. The field campaign site for the absolute calibration of the KOMPSAT series was established with KARI at the Goheung Aviation Center (lat $34.611^{\circ}$, lon $127.207^{\circ}$ ) in 2014. The Goheung Aviation Center is the site of a large-scale reclamation project and, except for the Goheung Aviation Center, the area is even and covered by agricultural land. While it could be affected by water vapor due to the nearby coast, the surface characteristics are even and mostly flat, which can minimize BRDF effects. The field campaign for the reflectancebased vicarious calibration was conducted three times at both Zuunmod and Goheung during the LEOP after launching KOMPSAT-3A. A reference target with a uniform $0.42 \sim 0.95-\mu \mathrm{m}$ reflectance tarp was installed (Figure 1 and 2).
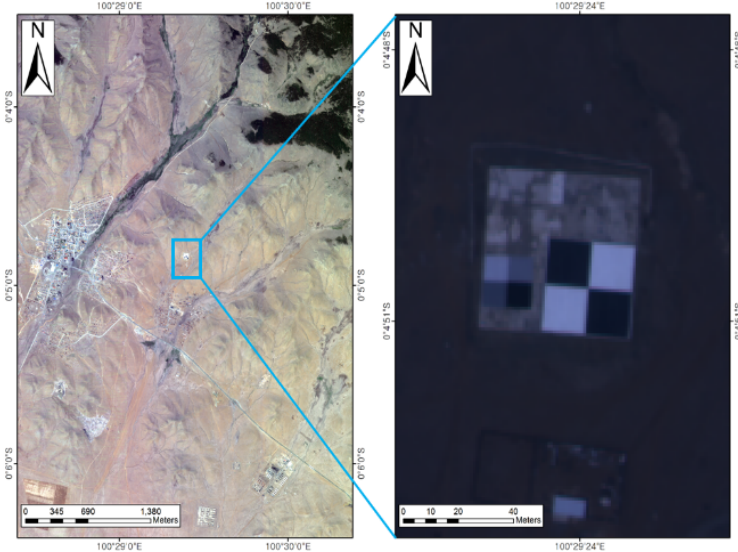

Figure 1. KOMPSAT-3A imagery at the Zuunmod site
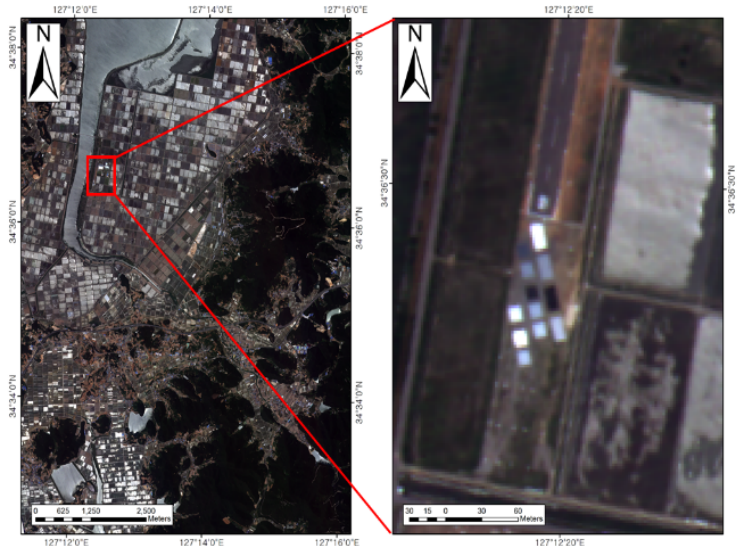

Figure 2. KOMPSAT-3A imagery at the Goheung site

\subsection{Atmospheric Correction}

The pathways and interactions that occur before and after solar radiance is reflected from the Earth- $\mu \mathrm{m}$ reflectance tarp was installed.talled.stics are even asensor $\left(L_{s}\right)$ can be described as equation (1):

$$
L_{S}=L_{T}+L_{P}
$$

where $L_{T}$ is total radiance from the target and $L_{P}$ is path radiance resulting from multiple scattering. Atmospheric correction is the process of minimizing or eliminating the contribution of path radiance $\left(L_{P}\right)$ from equation (1). Total radiance at the sensor $\left(L_{S}\right)$ can be estimated quantitatively from the RTC, which is used to quantitatively predict path radiance at a certain time and area to eliminate its impact (Jensen 2000). Satellite overpass observations of site surface reflectance and atmospheric data are used as RTC input values to predict sensor radiance (Table 2).

\begin{tabular}{ccccccr}
\hline \multicolumn{3}{c}{ Goheung } & \multicolumn{5}{c}{ Zuunmod } \\
& $05 / 26$ & $05 / 27$ & $05 / 28$ & $06 / 17$ & $06 / 18$ & $06 / 19$ \\
\hline $\begin{array}{c}\text { Aerosol } \\
\text { model } \\
\text { OMI ozone } \\
(\text { DU) }\end{array}$ & Rural & Rural & Rural & Desert & Desert & Desert \\
$\begin{array}{c}\text { Visibility } \\
(\text { Km) }\end{array}$ & 18.8 & 314.1 & 311.7 & 336.2 & 335.6 & 336.8 \\
$\begin{array}{c}\text { Water vapor } \\
(\mathrm{mb})\end{array}$ & 13.8 & 14.2 & 12.3 & 5.9 & 5.9 & 5 \\
$\begin{array}{c}\text { Tempe }\left(^{\circ}\right) \\
\text { Pressure } \\
(\mathrm{hPa})\end{array}$ & 30.9 & 29.2 & 27.2 & 27.9 & 25.3 & 28.2 \\
$\begin{array}{c}\text { Humidity } \\
(\%)\end{array}$ & 31.0 & 35.0 & 34.0 & 15.6 & 18.3 & 13.2 \\
\hline
\end{tabular}

Table 2. Margin settings for A4 size paper

In this study, the surface reflectance and TOA radiance of the reference tarp observed in the field campaign was estimated using MODO software based on MODerate resolution TRANsmission (MODTRAN) (SchllNon and Nieke 2005; Schl5; Sc 2011)

\subsection{Cross Validation}

This study cross-validated TOA reflectance with the Landsat- 8 OLI sensor, a multispectral sensor with similar bandwidth, to evaluate the vicarious calibration coefficient of KOMPSAT-3A AEISS-A sensor radiometric quality. To minimize atmosphere and Sun illumination by zenith angle, images were acquired on the same date and at similar times (within $2 \sim 3 \mathrm{hr}$ ).

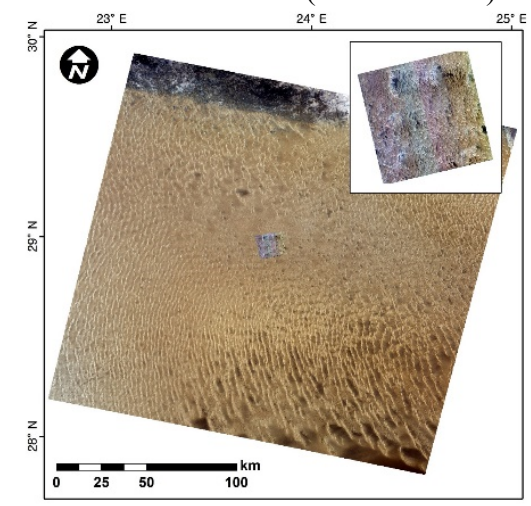

Figure 3. KOMPSAT-3A and Landsat-8 image in Libya-4 PICS 
The TOA reflectance at the sensor was used to reduce illumination differences among images and normalize for solar irradiance. Because atmospheric effects and surface topographic effects were not corrected, this included Earth surface reflectance and atmospheric reflectance (Cao et al. 2008). When comparing the radiometric quality obtained from the other sensors, the cosine effect of the different solar zenith angles due to differences in the time taken to obtain materials was removed by using TOA reflectance instead of TOA radiance. Equation (2) was used to calculate the TOA reflectance (atmospheric effects and surface

$$
\rho_{\lambda}=\frac{\pi \cdot L_{\lambda} \cdot d^{2}}{E \operatorname{SUN} N_{\lambda} \cdot \cos \theta_{s}}
$$

where $\rho_{\lambda}$ is planetary reflectance, $L_{\lambda}$ is spectral radiance at the sensor aperture of either KOMPSAT-3A or Landsat- $8\left(\mathrm{~W} / \mathrm{m}^{2} \mu \mathrm{m}\right.$ $\mathrm{sr}), E S U N_{\lambda}$ is the band-dependent mean solar exoatmospheric irradiance $\left(\mathrm{W} / \mathrm{m}^{2} \mu \mathrm{m}\right), \theta_{s}$ is the solar zenith angle (radians), and $d$ is the Earth-Sun distance (AU).

\section{RESULT AND DISSCUSSION}

\subsection{Radiometric Calibration}

The reflection coefficient was based on the reference tarp used for the KOMPSAT-3A L1R image DN. TOA radiance was calculated with a regression analysis based on equation (3):

$$
L_{\lambda}=\text { Gain } \times \text { Offset }
$$

where $L_{\lambda}$ is the predicted spectral radiance of each band at the sensor aperture using the RTC, gain and offset are the difference by band, sensor, and aperture (or time delay integration) setting (Ryan and Pagnutti 2009), The gain explains the sensitivity of the image DN to the radiance reaching the sensor and the spectral characteristics of the sensor (Belward and Valenzuela 1991).

We converted the reference tarp reflectance measurements into TOA radiance using the RTC and calculated the KOMPSAT-3A DN using a linear regression analysis. The absolute calibration using a vicarious approach for each spectral band and date gains of KOMPSAT-3A were calculated.
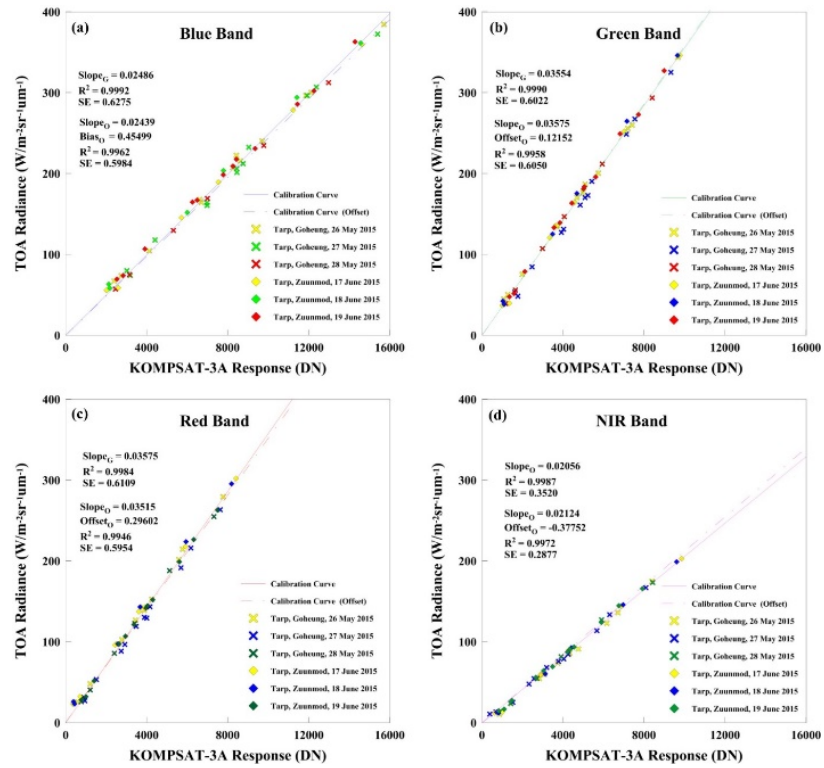

Figure 4. Figure placement and numbering

Figure 4 shows was the final absolute calibration curve used for the results. Table 3 shows the results for the absolute coefficient using a vicarious approach for KOMPSAT-3A. Using the $t$-test, the absolute coefficient was $<0.05$ in the linear regression. In addition, the correlation coefficient was $>0.99$ for all bands. The band coefficients at Zuunmod and Goheung were similar for KOMPSAT-3.

\begin{tabular}{ccccccc}
\hline Band & All & R2 & GH & ZM & STD & $\%$ diff. \\
\hline Blue & 0.02486 & 0.9992 & 0.02489 & 0.02479 & 0.004 & 0.40 \\
Green & 0.03554 & 0.9990 & 0.03532 & 0.03580 & 0.007 & -1.35 \\
Red & 0.03575 & 0.9984 & 0.03536 & 0.03638 & 0.011 & -2.88 \\
NIR & 0.02056 & 0.9987 & 0.02046 & 0.02070 & 0.003 & -1.17 \\
\hline
\end{tabular}

Table 3. The absolute calibration coefficients each site

\subsection{Cross Validation}

The TOA reflectance of Landsat- 8 and KOMPSAT-3A were compared for the calibration coefficient and the percentage difference was calculated using the Libya-4 PICS (Table 4).

\begin{tabular}{cccccc}
\hline Band & $\begin{array}{c}\text { L8 } \\
\text { (a) }\end{array}$ & $\begin{array}{c}\text { K3A } \\
\text { (b) }\end{array}$ & $\begin{array}{c}\text { Difference } \\
\text { (b)-(a) }\end{array}$ & $\begin{array}{c}\text { difference } \\
\text { (b)-(a)/(b) }\end{array}$ & $\begin{array}{c}\text { Std. } \\
\text { dev. }\end{array}$ \\
\hline Blue & 0.251 & 0.248 & -0.003 & -1.19 & 0.004 \\
Green & 0.335 & 0.323 & -0.012 & -3.65 & 0.007 \\
Red & 0.466 & 0.432 & -0.034 & -7.78 & 0.011 \\
NIR & 0.596 & 0.488 & -0.108 & -22.04 & 0.015 \\
\hline
\end{tabular}

Table 4. TOA Reflectance Validation Result (unit : \%)

From this, the blue and green bands were within $4 \%$. In the red band, the TOA reflectance of KOMPSAT-3A and Landsat- 8 differed by $\sim 8 \%$. However, in the NIR band, the average difference in TOA reflectance was $22 \%$ for the Libya site. This can be explained by the values in the band RSR of two sensors, which differed significantly from the NIR band and, unlike Landsat-8, the KOMPSAT-3A sensor reacted in a spectral region of $940 \mathrm{~nm}$ that is highly affected by water vapor absorption (Figure 5). This explains the lower TOA reflectance of KOMPSAT-3A in the NIR band than that of Landsat-8 (Brooke 2012).

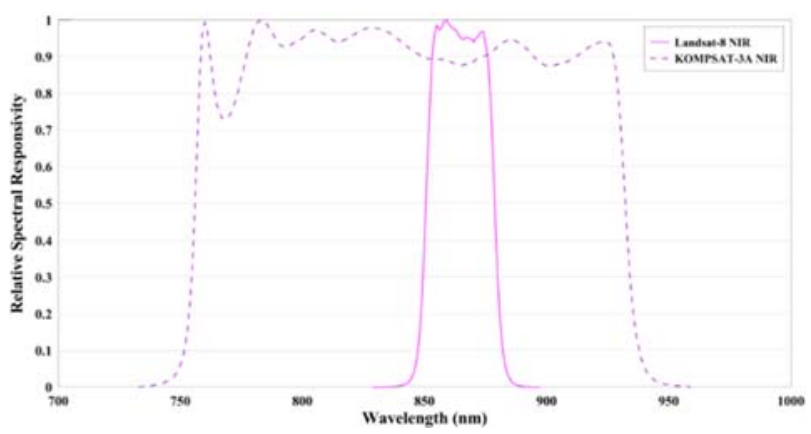

Figure 5. Comparison of the RSR in the near

\section{CONCLUSION}

In this study, with KARI and PKNU RSG, the relationship between the DN and sensor radiance was calculated using the radiometric calibration coefficient through absolute radiometric calibration of the KOMPSAT-3A sensor. 
The KOMPSAT-3A sensor was radiometrically calibrated using a reflectance-based method and, when choosing the coefficient, the $\mathrm{R}^{2}$ values of the fitted lines were $\sim 0.99$ for the multispectral bands and the correlation between TOA radiance and RSR by the KOMPSAT-3A sensor at the Zuunmod and Goheung sites were significant for the multispectral bands. The percentage difference between the two sets of coefficients at the Zuunmod and Goheung sites was within $1.5 \%$ for the blue, red, and NIR bands and $\sim 3 \%$ for the green band.

For the calibration coefficient assessment, measuring the TOA reflectance of Landsat- 8 and KOMPSAT-3a were performed using Libya-4 PICS almost simultaneously. The difference was within 3\% (percentage difference, $7 \%$ ) for the blue, green, and red bands, while the NIR band had a difference within $10 \%$ (percentage difference, 22\%). This likely resulted in the band RSR difference, as the difference between Landsat- 8 and KOMPSAT-3A NIR band is due to the water vapor region in the NIR band.

The absolute radiometric calibration method used in this paper provides basic data for maintaining the radiometric quality of KOMPSAT-3A without an onboard calibrator. Absolute calibrations using a vicarious approach and cross-calibrations will be important to further improve sensor monitoring.

\section{ACKNOWLEDGEMENTS}

This work was supported by the BK21 Plus project of The Research management team of Earth Environmental Hazard System at Pukyong National University

\section{REFERENCES}

Belward, A.S., and C.R. Valenzuela. 1991. Remote sensing and geographical information systems for resource management in developing countries. Dordrecht, Netherlands: Kluwer Academic.

Brooke, B. 2012. "Characterization of the Libyan Desert in Support of Vicarious Calibration.” Master's thesis, University of Northeastern.

Cao, C., X. Xiong, A. Wu, and W. Wu. 2008 "Assessing the consistency of AVHRR and MODIS L1B reflectance for generating Fundamental Climate Data Records." Journal of Geophysical Research: Atmospheres 113 (D9): 1984-2012. doi:10.1029/2007JD009363.

Jensen, J. R. 2000. Remote Sensing and the Environment. Upper Saddle River, NJ: Prentice-Hall.

Kim, J. S., C. G. Jin, C. U. Choi, and H. Y. Ahn. 2015. "Radiometric characterization and validation for the KOMPSAT-3 sensor." Remote Sensing Letters 6 (7): 529-538. doi: 10.1080/2150704X.2015.1054043

Lee, S., C. Jin, C. Choi, H. Lim, Y. Kim, and J. Kim. 2012. "Absolute Radiometric Calibration of the KOMPSAT-2 Multispectral Camera Using a Reflectance-Based Method and Empirical Comparison with IKONOS and Quickbird Images." Journal of Applied Remote Sensing 6 (1): 063594. doi:10.1117/1.JRS.6.063594.

Naughton, D., A. Brunn, J. Czapla-Myers, S. Douglass, M. Thiele, H. Weichelt, and M. Oxfort. 2011. "Absolute Radiometric Calibration of the Rapideye Multi-Spectral Imager Using the Reflectance-Based Vicarious Calibration Method." Journal of Applied Remote Sensing 5. doi:10.1117/1.3613950.
Pagnutti, M., R. E. Ryan, M. Kelly, K. Holekamp, V. Zanoni, K. Thome, and S. Schiller. 2003. "Radiometric Characterization of IKONOS Multispectral Imagery." Remote Sensing of Environment 88 (1): 53-68. doi:10.1016/j.rse.2003.07.008.

Schläpfer， D. 2011. MODO: MODTRAN®-5 for Remote Sensing Applications User Manual. Accessed 15 January 2016. http://rese.ch/pdf/MODO_Manual.pdf

Schläpfer, D., and J. Nieke. 2005. "Operational Simulation of at Sensor Radiance Sensitivity Using the MODO/MODTRAN Environment." Proceedings of the EARSeL Fourth Workshop on Imaging Spectroscopy, Warsaw, April 26-29. 